\title{
The doses of plasmid backbone plays a major role in determining the HBV clearance in hydrodynamic injection mouse model
}

Xian Wang ${ }^{1,3+}$, Jianmin Zhu ${ }^{2+}$, Yong Zhang ${ }^{4}$, Yue $\mathrm{Li}^{1}$, Tai Ma', Qun $\mathrm{Li}^{1}$, Jiegou Xu ${ }^{1}$ and Long $\mathrm{Xu}^{1 *}$

\begin{abstract}
Background: Hepatitis B virus (HBV) chronically infects approximately 350 million people worldwide, causing a major risk of liver disease and hepatocellular carcinoma (HCC). Many mouse models have been tried to establish HBV infection through injection with various HBV-containing plasmids. However, it is not well understood that different plasmids, all of which contain the similar HBV genome, even the same plasmids with different dose, results in opposite immune responses toward HBV.
\end{abstract}

Methods: In this study, we investigated the role of HBV-containing plasmid backbones and the HBcAg in determining the HBV persistence. C57BL/6 mice were injected hydrodynamically with $6 \mu \mathrm{g}$ or $20 \mu \mathrm{g}$ of WT pAAV/HBV1.2 plasmid, e/core-null pAAV/HBV1.2 plasmid, or none-HBV genome pAAV/control plasmid. Serum levels of HBV-related markers were measured by quantitative immunoradiometric assay (IRMA). Liver HBcAg expression was detected by immunohistochemical staining. The mRNA levels of cytokines and Th1-related immune factors were quantified by qRT-PCR.

Results: All mice injected with $6 \mu \mathrm{g}$ of the pAAV/HBV1.2 plasmid shows HBsAg positive at week 6 after hydrodynamic injection (AHI) as previously investigated. However, the mice injected with $20 \mu \mathrm{g}$ pAAV/HBV1. 2 or $6 \mu \mathrm{gpAAV/HBV1.2} \mathrm{plus} \mathrm{14 \mu gpAAV/control} \mathrm{plasmid} \mathrm{results} \mathrm{in} \mathrm{HBV} \mathrm{clearance} \mathrm{within} 4$ weeks AHI, indicating the antiHBV activity is induced by $20 \mathrm{\mu g}$ plasmid DNA, but not by the inserted viral genome. This anti-HBV activity is independent of HBCAg and Toll like receptor (TLR) signaling pathway, since the lack of HBCAg in PAAV/HBV1.2 plasmid or stimulation with TLRs agonists does not influence the kinetics of serum HBsAg in mice. The mRNA levels of t-bet and cxcr3 were dramatically up-regulated in the liver of the mice injected with $20 \mu \mathrm{g}$ plasmid DNA.

Conclusion: Our studies demonstrate that plasmid backbones are responsible for modulating immune responses to determine HBV persistence or clearance in our HBV mouse model by hydrodynamic injection of HBV-containing plasmid, and Th1 cells play key roles on HBV clearance.

Keywords: Plasmid backbone, Hepatitis B virus, Hydrodynamic injection, HBcAg, Mouse model

\footnotetext{
* Correspondence: xulong@ahmu.edu.cn

${ }^{+}$Xian Wang and Jianmin Zhu contributed equally to this work.

${ }^{1}$ School of Basic Medical Sciences, Anhui Medical University, 81\#Mei Shan

Road, Hefei 230032, Anhui, China

Full list of author information is available at the end of the article
}

(c) The Author(s). 2018 Open Access This article is distributed under the terms of the Creative Commons Attribution 4.0 International License (http://creativecommons.org/licenses/by/4.0/), which permits unrestricted use, distribution, and reproduction in any medium, provided you give appropriate credit to the original author(s) and the source, provide a link to the Creative Commons license, and indicate if changes were made. The Creative Commons Public Domain Dedication waiver (http://creativecommons.org/publicdomain/zero/1.0/) applies to the data made available in this article, unless otherwise stated. 


\section{Background}

Hepatitis B virus (HBV), a member of the hepadnavirus group, is a double-stranded DNA virus which replicate by reverse transcription [1]. It causes acute and chronic viral hepatitis which is a major public health problem that affects about 350 million people worldwide. Moreover, $25 \%$ persistent HBV sufferers would develop into hepatic cirrhosis and hepatocellular carcinoma [2-4]. However, the precise mechanisms of HBV immunopathogenesis and the virus persistence are not well understood yet.

Natural HBV infection only occurs in human being, chimpanzee and tree shrew [5]. So, lack of suitable mouse models is an obstacle to explore the immunological mechanism of HBV. Although the appearance of HBV-transgenic mice has promoted $\mathrm{HBV}$ related research [6], it is not a good model to investigate the immunological mechanisms of $\mathrm{HBV}$ because of the central tolerance to $\mathrm{HBV}$-related antigens. To overcome this challenge, many researchers created HBV persistence models in immunocompetent mice through hydrodynamic injection of $\mathrm{HBV}$ genome-containing plasmids, by which the injected plasmids could mainly target hepatocytes [7]. In these $\mathrm{HBV}$ persistent mice, viral replication intermediates, transcripts, and all HBV related proteins can be detected in the liver tissues for several months. However, hydrodynamic injection of different plasmids, in spite of containing same HBV genome, or the same plasmids at different doses induce totally different immune responses toward HBV and subsequently result in HBV persistence or HBV clearance [8-11]. This opposite results suggest that plasmid backbones other than HBV genome are involved in triggering innate immunity [12], which eventually influence the status of HBV infection.

In the present study, through hydrodynamic injection with pAAV/HBV1.2 plasmid which was widely used to establish HBV-carrier mouse models in our previous studies [13-16], we found that the plasmid-injected mice showed a completely different immune response toward HBV. Six micrograms of the pAAV/HBV1.2 pasmids induced a long-term humoral immune tolerance accompanied by persistent serum HBsAg levels and $\mathrm{HBcAg}$ in liver tissue, while $20 \mu \mathrm{g}$ pAAV/HBV1.2 plasmid resulted in rapid HBV clearance within 4 weeks, along with significantly increased serum anti-HBs antibody levels. Finally, we found the doses of plasmid backbones, but not HBV-related components, played critical roles in determining the HBV clearance in our mouse model.

\section{Methods}

\section{Animals}

Male C57BL/6 mice (5-6 weeks old) were purchased from the Shanghai Experimental Animal Center (Shanghai, China). The mice were maintained under specific pathogen-free conditions and used according to the guidelines outlined in the Guide for the Care and Use of Laboratory Animals.

\section{Plasmid and mouse model}

WT pAAV/HBV1.2 and e/core-null pAAV/HBV1.2 plasmid were kindly provided by Dr. Peijer Chen (National Taiwan University). All the plasmids were isolated by using an endotoxin-free midi kit (Qiagen, Inc., Valencia, CA, USA). Hydrodynamic injection of the different plasmids into mice was performed as described [7]. Serum $\mathrm{HBsAg}$, anti-HBs, and anti-HBc antibody levels were determined using commercially available immunoradiometric assay (IRMA) kits (Beijing North Institute of Biological Technology, Beijing, China).

\section{Immunohistochemistry}

Liver samples were fixed in $10 \%$ neutral buffered formalin and embedded in paraffin. Liver sections were stained for $\mathrm{HBcAg}$ using rabbit antibodies against HBcAg (Dako, Carpinteria, CA) followed by biotinylated anti-rabbit IgG and streptavidin-HRP conjugates (Zhongshan Goldenbridge, Beijing, China). The stains were developed with a DAB kit (Vector Laboratories).

\section{Reverse transcriptase - PCR}

Total RNA was isolated from the liver tissues or liver mononuclear cells (MNCs) at day 3 AHI by TRizol reagent (Invitrogen). Reverse transcription was performed by M-MLV (Invitrogen). Realtime fluorescence quantitative PCR was based on SYBR Premix Ex Tap (TaKaRA), and the reactions were performed with a denaturation step at $94{ }^{\circ} \mathrm{C}$ for 20 s, annealing at $60{ }^{\circ} \mathrm{C}$ for 30 s, and extension at $72{ }^{\circ} \mathrm{C}$ for 30 s for 40 cycles. Results were normalized to GAPDH mRNA expression. PCR primers are as followed:

tlr3, TTGTCTTCTGCACGAACCTG (f) and CGCA ACGCAAGGATTTTATT (r);

tlr4, ACCTGGCTGGTTACACGTC (f) and CTGC

CAGAGACATTGCAGAA(r);

tlr7, GGAAATTGCCCTCGATGTTA (f) and CAAA

AATTTGGCCTCCTCAA (r);

tlr8, GAAGCATTTCGAGCATCTCC (f) and GAAG

ACGATTTCGCCAAGAG (r);

tlr9, ACTGAGCACCCCTGCTTCTA (f) and AGAT

TAGTCAGCGGCAGGAA (r);

ifn- $\alpha$, AGGACAGGAAGGATTTTGG (f) and GCTG

CTGATGGAGGTCAT (r);

ifn- $\beta$, CACAGCCCTCTCCATCAAC (f) and GCAT CTTCTCCGTCATCTCC (r);

ifn- $\gamma$, TGCATCTTGGCTTTGCAGCTCT (f) and TGGACCTGTGGGTTGTTGACCT (r);

il-6, ACAACCACGGCCTTCCCTAC (f) and ACAA TCAGAATTGCCATTGCAC (r); 
il-12, GTGAACCTCACCTGTGACACGC AATACTTCTCATAGTCCCTTTGG (r); il-15, CCAACTGGATAGATGTAAGATA

GTCAGGACGTGTTGATGAACAT (r); tgf- $\beta, \quad$ GTACAGCAAGGTCCTTGCCCT

TAGTAGACGATGGGCAGTGGC (r); t-bet, GCCAGGGAACCGCTTATATGTC CTGTGAGATCATATCCTTGGGCTG (r); cxcr3, TGTAGCCCTCACCTGCATAGTTGT (f) and

(f) and

(f) and

(f) and

(f) and ACCACAGTCCATGCCATCAC (f) and TCCACCACC CTGTTGCTGTA (r).

$\mathrm{f}$ and $\mathrm{r}$ mean forward and reverse pimers.

\section{Statistical analysis}

Unpaired two-tailed Student's $t$-test was used for statistical analyses. Data was expressed as means \pm SEM, and data were considered statistically significant when $P$ values were $<0.05$. Significance was denoted as ${ }^{*} P<0.05,{ }^{* *} P<0.01$, and ${ }^{* * *} P<0.001$.

\section{Results}

Injection of $20 \mu \mathrm{g}$ pAAV/HBV1.2 plasmids induced anti-HBV activity in mice model

Our previous studies have revealed that hydrodynamic injection of $6 \mu \mathrm{g}$ pAAV/HBV1.2 could establish long-term HBsAg-persistent mice and maintain the tolerant state via induction of HBV specific Tr1 like cells [13, 17]. In this study, C57BL/6 mice were injected with $6 \mu \mathrm{g}$ or $20 \mu \mathrm{g}$ pAAV/HBV1.2 plasmids. In the $20 \mu \mathrm{g}$ group, the serum levels of HBsAg and HBeAg dropped quickly and all the mice were HBsAg negative at 5 weeks post injection (wpi) (Fig. 1a-c), indicating the induction of anti-HBV immunity in theses mice. However, in the $6 \mu \mathrm{g}$ group, the HBsAg and HBeAg level declined much more slowly (Fig. 1a, b), and all mice were still HBsAg positive at 6 wpi (Fig. 1c). Also, $80 \%$ of the mice injected with $20 \mu \mathrm{g}$ pAAV/HBV1.2 plasmids produced anti-HBs antibody in the serum, while only $25 \%$ of those receiving $6 \mu \mathrm{g} \mathrm{pAAV} / \mathrm{HBV} 1.2$ plasmid were anti-HBs positive at week $11 \mathrm{AHI}$ (Table 1). In addition, cytoplasmic and nucleic $\mathrm{HBcAg}$ was observed in the liver of $6 \mu \mathrm{g}$ group, but not in that of the $20 \mu \mathrm{g}$ group, at 6 wpi (Fig. 1d). Overall, hydrodynamic injection of $6 \mu \mathrm{g}$ pAAV/HBV1.2 induced immune tolerance to keep HBV persistence, while injection of $20 \mu \mathrm{g}$ pAAV/HBV1.2 triggerd anti-HBV immune responses leading to HBV clearance.

Anti-HBV activity triggered by $20 \mu \mathrm{g}$ pAAV/HBV1.2 plasmids did not break HBV tolerance induced by $6 \mu \mathrm{g}$ pAAV/HBV1.2 plasmids

To test whether anti-HBV activity triggered by $20 \mu \mathrm{g}$ pAAV/HBV1.2 plasmids, as well as IL-12-based vaccination, could reverse $6 \mu \mathrm{g}$ pAAV/HBV1.2 plasmid -induced HBV persistence [18], HBV-persistent mice established by prior injection with $6 \mu \mathrm{g}$ pAAV/HBV1.2plasmid were
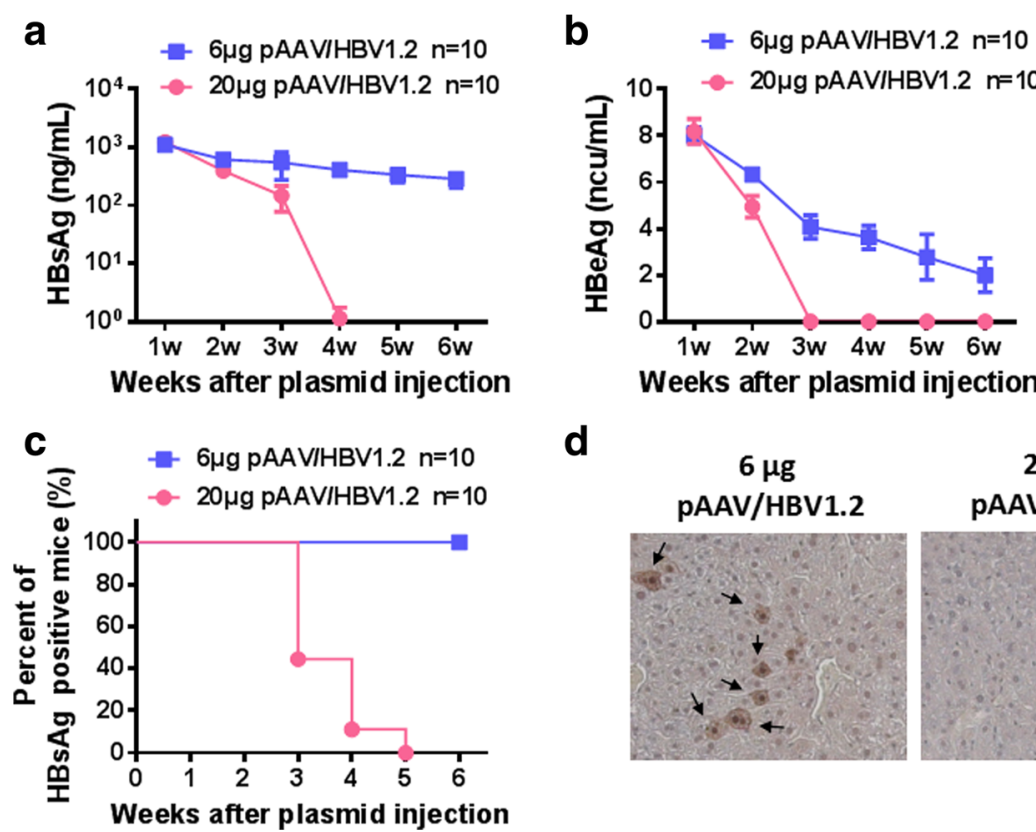

d

Weeks after plasmid injection

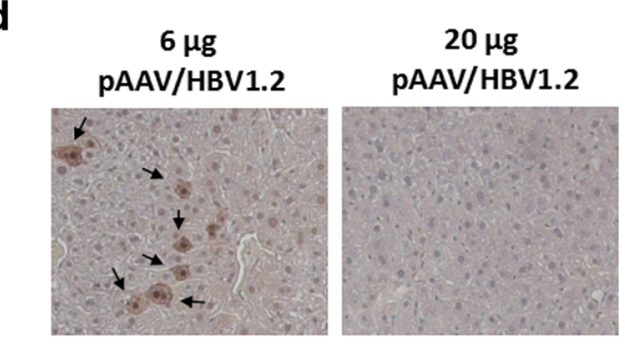

Fig. 1 The doses of pAAV/HBV1.2 plasmid determine HBV persistence in C57BL/6 mice. C57BL/6 mice were hydrodynamically injected with $6 \mu \mathrm{g}$ or $20 \mu \mathrm{g}$ pAAV/HBV1.2 plasmid. Serum levels of HBsAg (a) and HBeAg (b) were measured at indicated time points. c Positive rate of serum HBsAg after HBV plasmid injection. d Immunohistochemical staining for HBCAg in liver sections of mice at week 6 after injection with $6 \mu \mathrm{g}$ or $20 \mu \mathrm{g}$ pAAV/HBV1.2 plasmid. (original magnification: 100x). Results represent 2 independent experiments ( $n=10 /$ group) 
Table 1 Appearance of anti-HBs antibody at indicated time points AHI with different HBV plasmids DNA

\begin{tabular}{lllll}
\hline HBV plasmid & Week 1-3 & Week 4 & Week 5 & Week 11 \\
\hline $6 \mu \mathrm{g} \mathrm{WT} \mathrm{pAAV/HBV1.2}$ & $0 / 20$ & $0 / 20$ & $0 / 20$ & $5 / 20$ \\
$20 \mu \mathrm{g} \mathrm{WT} \mathrm{pAAV/HBV1.2}$ & $0 / 20$ & $0 / 20$ & $4 / 20$ & $16 / 20$ \\
$20 \mu \mathrm{g}$ e/core-null pAAV/HBV1.2 & $0 / 10$ & $1 / 10$ & $3 / 10$ & $10 / 10$ \\
$6 \mu \mathrm{g} \mathrm{WT} \mathrm{pAAV/HBV1.2}$ & $0 / 20$ & $1 / 20$ & $5 / 20$ & $18 / 20$ \\
plus $14 \mu \mathrm{g}$ pAAV/Control & & & & \\
\hline
\end{tabular}

The number of mice in each group positive for anti-HBs antibody

received second hydrodynamic injection with $20 \mu \mathrm{g}$ pAAV/HBV1.2plasmid (Fig. 2a). After the second injection, serum levels of HBsAg decreased significantly in normal saline (NS)-pretreated mice and became negative at 5 wpi, while $100 \%$ of HBV-persistent mice still kept HBsAg positive in serum, as well as $\mathrm{HBcAg}$ in liver section, at 5 wpi (Fig. 2b-c).

\section{HBV clearance triggered by $20 \mu \mathrm{g}$ pAAV/HBV1.2 plasmid was independent on $\mathrm{HBCAg}$}

It was reported that $\mathrm{HBcAg}$ played an important role in inducing anti-HBV immunity [19]. Next we tested whether the anti-HBV activity triggered by $20 \mu \mathrm{g}$ pAAV/HBV1.2 plasmid was dependent on elevated $\mathrm{HBcAg}$ expression, which might be due to the higher concentration of injected plasmids. We indeed found that the percentage of $\mathrm{HBcAg}$ positive hepatocytes was much higher in the $20 \mu \mathrm{g}$ group than those in the $6 \mu \mathrm{g}$ group (Fig. 3a). Consistently, serum level of anti-HBc antibody was increased significantly in the $20 \mu \mathrm{g}$ group (Fig. $3 \mathrm{~b})$. To further address this point, e/core-null pAAV/HBV1.2 plasmids that was lack of e/core gene was tested. Surprisingly, the serum levels and the persistence rates of $\mathrm{HBsAg}$ in mice receiving $20 \mu \mathrm{g}$ e/core-null mutant plasmids were entirely similar to those of the mice receiving $20 \mu \mathrm{g}$ WT pAAV/HBV1.2 plasmids (Fig. 3c, d). In addition, the serum levels of anti-HBs displayed the similar kinetics at different time points between these two groups (Table 1). These data indicated that HBV clearance caused by injection of $20 \mu \mathrm{g}$ pAAV/HBV1.2 plasmids was not associated with $\mathrm{HBcAg}$.

HBV clearance triggered by $20 \mu \mathrm{g}$ pAAV/HBV1.2 plasmid was dependent on the doses of plasmid backbone

Another possibility counting for HBV clearance or persistence is the dose of the injected plasmid DNA, which was reported to be recognized by various pattern recognition receptors (PRRs) and eventually trigger innate immune responses [20]. To test this possibility, pAAV/HBV1.2 plasmids and the control plasmids lacking the HBV genome were injected into C57BL/6 mice. $6 \mu \mathrm{g}$ pAAV/HBV1.2 plasmids were applied in group A; $6 \mu \mathrm{g}$ pAAV/HBV1.2 plus14 $\mu \mathrm{g}$ the control plasmids in group $\mathrm{B}$; and $20 \mu \mathrm{g}$ pAAV/HBV1.2 plasmids in group $C$, respectively. The serum HBsAg levels of the group B dropped as quickly as the group $C$, and revealed similar kinetics of serum $\mathrm{HBsAg}$ and anti-HBs at different time points. However, these parameters in the group A were totally different from those in the group $\mathrm{B}$, although the group $\mathrm{A}$ and $\mathrm{B}$ received the same doses of $6 \mu \mathrm{g}$ HBV genome DNA (Fig. 4a, b; Table 1). These data indicated that anti-HBV activity was determined by the dose of plasmid backbone, but not $\mathrm{HBV}$-related proteins in our mouse model.

To test whether $20 \mu \mathrm{g}$ pAAV/HBV1.2 plasmids-caused HBV clearance was mediated by immune response toward the plasmid backbone or toward HBV-related

a
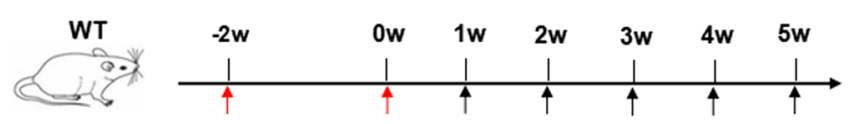

1 st H.I.

$2^{\text {nd }}$ H.I. detect serum levels of HBsAg

b

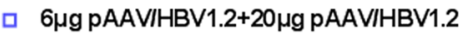

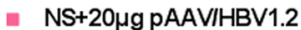

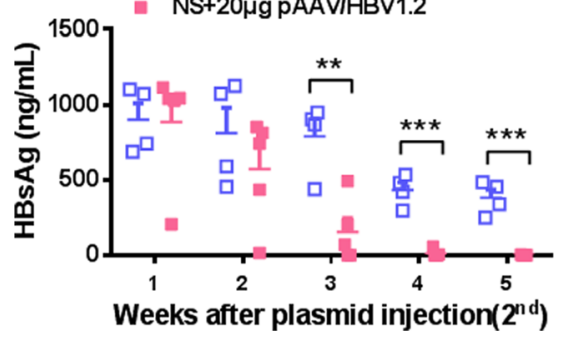

C
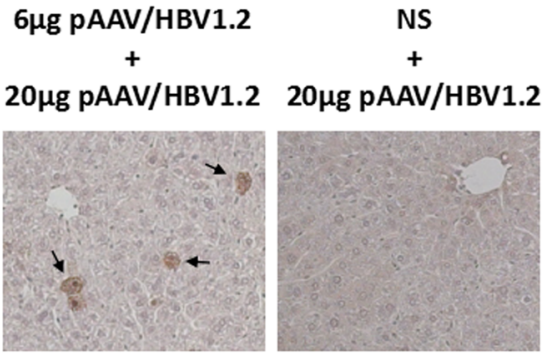

Fig. 2 HBV tolerant mice still keep HBV persistence after injection with $20 \mu \mathrm{g}$ pAAV/HBV1.2. a WT mice were hydrodynamically injected with NS or $6 \mu \mathrm{g}$ pAAV/HBV1.2 plasmid, and then the mice received second injection with $20 \mu \mathrm{g}$ pAAV/HBV1.2 plasmid. Serum levels of HBsAg were examined at indicated time points. The serum levels of HBsAg (b) and liver HBcAg expression (c) were shown. Results represent 2 independent experiments ( $n=5 /$ group) 
a

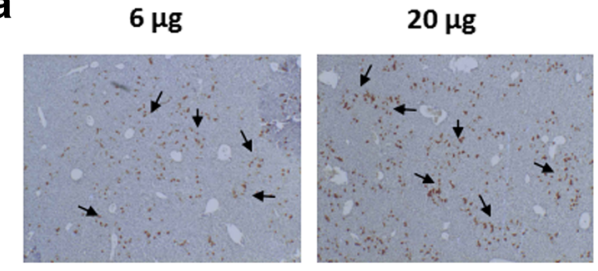

C

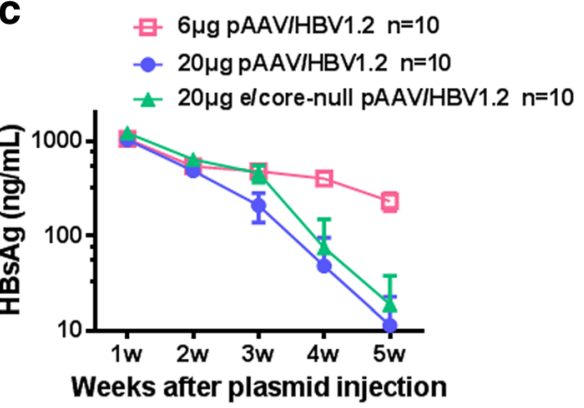

b $\quad$ 6 2 g pAAVIHBV1.2 $n=10$

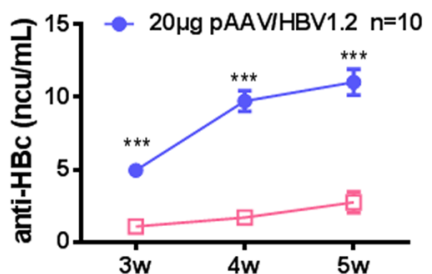

Weeks after plasmid injection

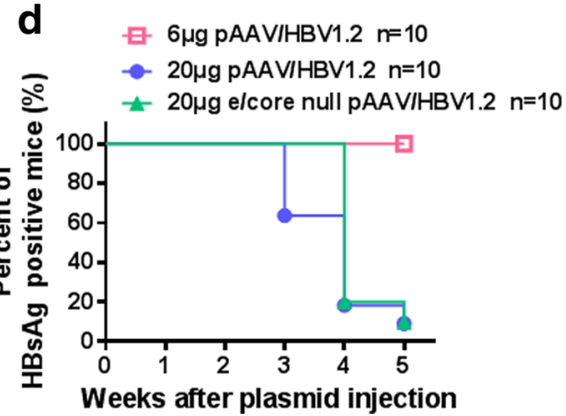

Fig. $3 \mathrm{HBV}$ clearance still occurs in $20 \mathrm{\mu g}$ e/core-null PAAV/HBV1.2 plasmid-injected mice. WT mice were hydrodynamically injected with $6 \mu \mathrm{g}$ or $20 \mathrm{\mu g}$ pAAV/HBV1.2 plasmid. Liver HBCAg expression (a) was detected at day $3 \mathrm{AHI}$. (original magnification: 40X) (b) serum levels of anti-HBC was measured at indicated mice. c, d C57BL/6 mice were hydrodynamically injected with various plasmids as shown. Serum levels of HBsAg were measured at indicated time points. $\mathbf{d}$ Positive rate of serum HBsAg after HBV plasmid injection

antigens, we injected $20 \mu \mathrm{g}$ the control or $20 \mu \mathrm{g}$ pAAV/ HBV1.2 plasmids into mice 1 week prior to injection of $6 \mu \mathrm{g}$ pAAV/HBV1.2 (Fig. 5a). Three weeks later, the mice pre-treated with $20 \mu \mathrm{g}$ of the control plasmids still kept HBV persistence, similar to those pre-treated with NS. However, $80 \%$ of mice pre-treated with $20 \mu \mathrm{g}$ pAAV/ HBV1.2 developed anti-HBV activity and eliminated the serum HBsAg (Fig. 5b). These data suggested that the plasmid backbone, which must been injected together with $6 \mu \mathrm{g}$ pAAV/HBV1.2, had an adjuvant effect to induce the immune activity toward HBsAg in a nonspecific manner. To further address this, we found co-injection of $6 \mu \mathrm{g}$ pAAV/HBV1.2 and $14 \mu \mathrm{g}$ HBV-irrelevant pRNT-H1.1 plasmid could also lead to the significant decrease of HBsAg levels at week 4 AHI (Fig. 5c).
The mRNA levels of toll like receptors (TLRs) and Th1related immune factor at day $3 \mathrm{AHI}$

To explore a possible link between $20 \mu \mathrm{g}$ plasmid DNA caused HBV clearance and TLRs signaling pathways [21, 22], serum levels of HBsAg were monitored from mice receiving $6 \mu \mathrm{g}$ pAAV/HBV1.2 mixed with agonists of TLR3, TLR4, TLR7/8, and TLR9 respectively. All these mice have shown the decreased levels of HBsAg at week 1 or week 4 , but none of mice were $\mathrm{HBsAg}$ negative at week 4 AHI (Fig. 6a-b). Also, the relative mRNA levels of TLR3, TLR4, TLR7, TLR8, or TLR9 kept unaltered in liver tissue of mice receiving NS or $20 \mu \mathrm{g}$ of the control plasmid (Fig. 6c), suggesting the TLRs signaling pathway did not account for HBV elimination in this model.
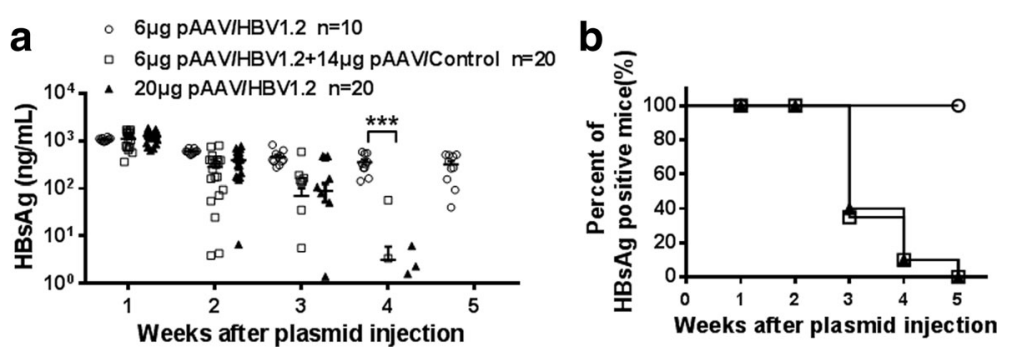

Fig. 4 The doses of plasmid backbone are critical for HBV persistence. WT mice were hydrodynamically injected with $6 \mu \mathrm{gg}$ pAAV/HBV1.2, $6 \mu \mathrm{g}$ pAAV/HBV1.2 plus $14 \mu \mathrm{g}$ pAAV/control, and $20 \mu \mathrm{g}$ pAAV/HBV1.2 respectively. Serum levels of HBsAg (a) and positive rate of serum HBsAg (b) were shown at indicated time points 

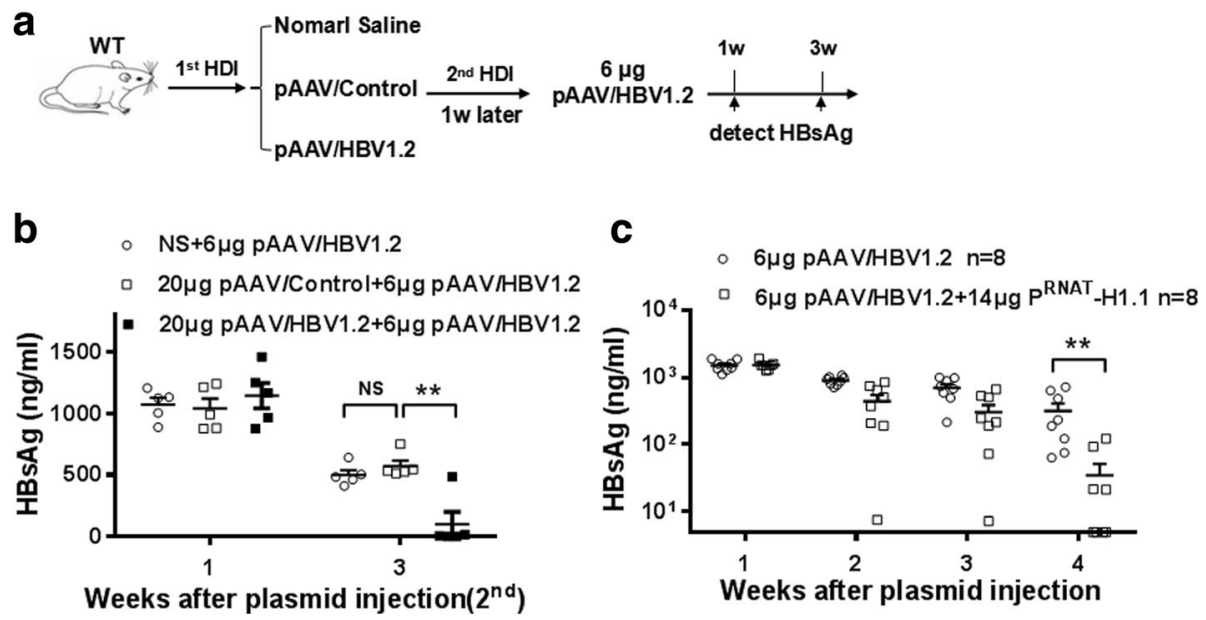

Fig. 5 The plasmid backbone causes HBV clearance in unspecific manner. a WT mice received first hydrodynamic injection with NS, 20 Mg pAAV/ Control plasmid, or $20 \mu \mathrm{g}$ pAAV/HBV1.2 plasmid, and then followed by second injection with $6 \mu \mathrm{g}$ pAAV/HBV1.2 plasmid 1 week later. b Serum levels of HBsAg were determined at week 1 and 3 AHI. c Serum levels of HBsAg were detected at the indicated time points after hydrodynamical injection with $6 \mu \mathrm{g}$ of pAAV/HBV1.2 mixing with or without $14 \mu \mathrm{g}$ pRNT-H1.1 plasmids respectively. Results represent 2 independent experiments $(n=5-8 /$ group $)$

We further detected the mRNA levels of cytokines and Th1-related immune factors in the liver MNCs 3 days AHI. No obvious difference in the mRNA levels of ifn- $\alpha$, ifn- $\beta$, tgf- $\beta$, il- 6 , il- 12 and il- 15 was found between mice receiving NS or $20 \mu \mathrm{g}$ of the control plasmids. However, the mRNA levels of Th1-related immune factors, includ-

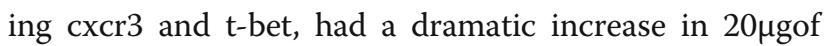
the control plasmid group. Also, interferon (IFN) $-\gamma$ and IL-12 were slightly up-regulated (Fig. 7 and data not shown). These data suggested Th1 cells might play a critical role in HBV clearance caused by high doses of HBV plasmids in the TLRs independent manner.

\section{Discussion}

A completely opposite immune responses toward $\mathrm{HBsAg}$ are induced in adult C57BL/6 mice after injection with $6 \mu \mathrm{g}$ or $20 \mu \mathrm{g}$ of pAAV/HBV1.2 plasmids. Our results have shown that HBV clearance still occurs in mice
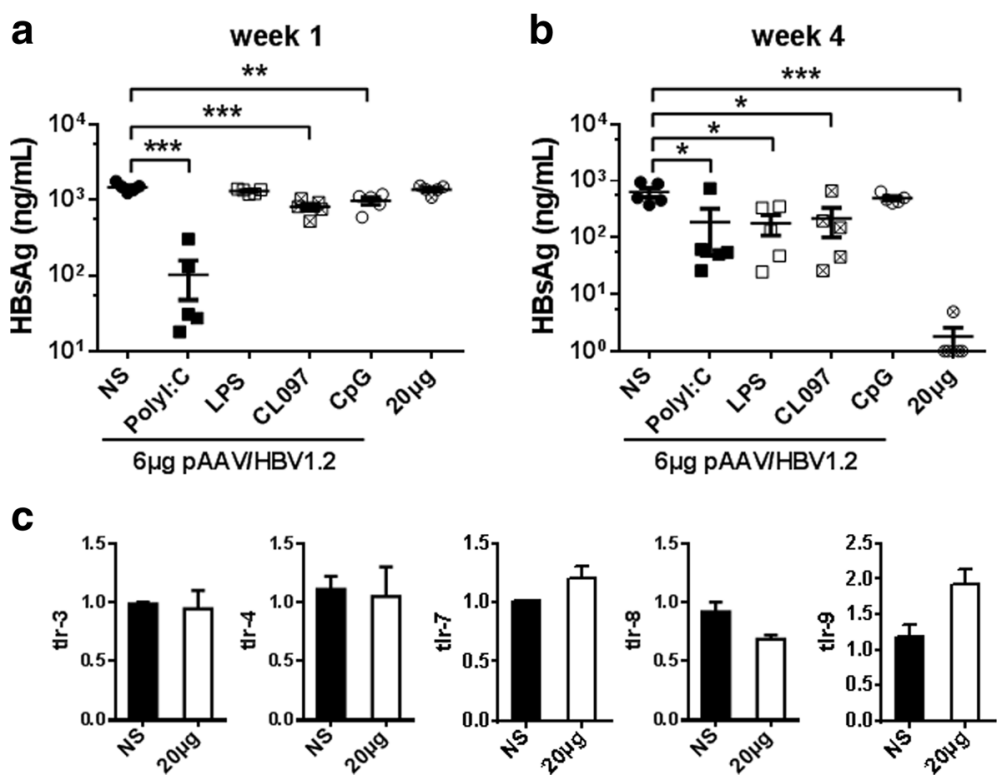

Fig. 6 The TLRs signaling pathway is not critical for HBV clearance in high dose HBV-plasmid injection. C57BL/6 mice were injected with $6 \mu \mathrm{g}$ pAAV/HBV1.2 mixing with different TLR activators, including: $10 \mu \mathrm{g}$ of poly I:C, LPS, CL097 and CpG, respectively. Serum levels of HBsAg were measured at week 1 (a) and week 4 (b) AHI. c The mRNA levels of TLRs in liver tissue was detected by real time PCR at day 3 after injection of NS or $20 \mathrm{\mu g}$ pAAV/control plasmid. Results represent 2 independent experiments ( $n=5 / \mathrm{group}$ ) 

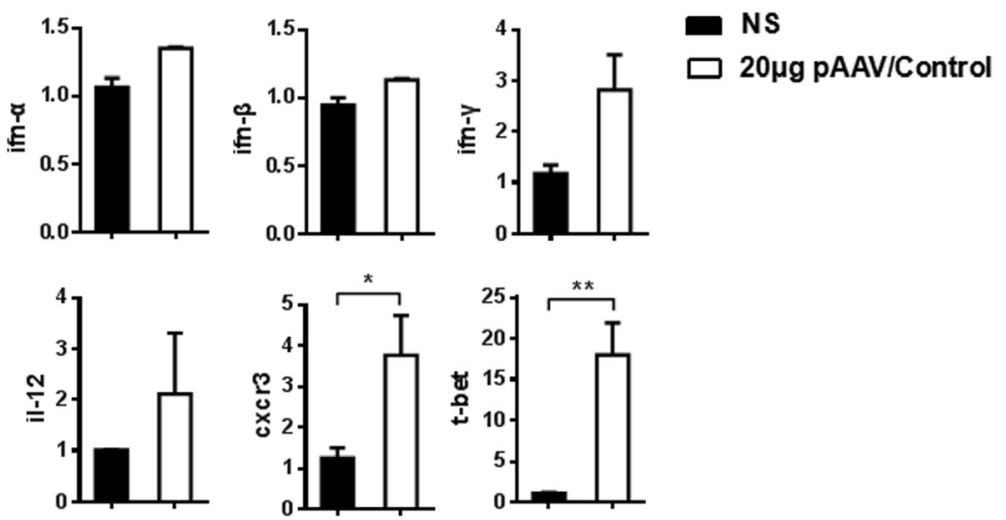

Fig. 7 Relative mRNA expression. Relative amount of mRNA in liver MNCs was detected by real time PCR at day 3 after hydrodynamic injection with NS or $20 \mu \mathrm{g}$ pAAV/control plasmid. Results represent 2 independent experiments ( $n=$ at least 3/group)

injected with20 $\mu \mathrm{g}$ of the e/core-null pAAV/HBV1.2 plasmids (Fig. 3c-d), and HBV persistence induced by $6 \mu \mathrm{g}$ pAAV/HBV1.2 plasmid is broken by mixing with $14 \mu \mathrm{g}$ of the control plasmid or with even other irrelevant plasmids at injection time (Fig. 4 and Fig. 5c). Therefore, the doses of plasmid backbone rather than the levels of HBV-related antigens played determining roles in triggering anti-HBV activity, resulting in the HBV clearance within 4 weeks AHI in our study.

Many components of HBV and plasmid backbones, including DNA from replication templates and RNA derived from transcriptional intermediate, are appropriate agonists of TLRs, RIG-I,NALP3, AIM2, IFI16 and so on $[23,24]$. There are a large amount of innate immune cells [25] and accumulation of injected HBV plasmids AHI in the liver [7]. Therefore, the innate immune responses triggered by the plasmid DNA in the liver microenvironment were considered to be a critical factor in preventing HBV tolerance $[26,27]$. Inflammatory response triggered by plasmid DNA should be induced both in the $6 \mu \mathrm{g}$ and the $20 \mu \mathrm{g}$ group, the opposite immune responses toward HBsAg induced by these two doses raise a possibility that the certain threshold for inflammatory response may exist to regulate the balance between liver tolerance and immune activation [28]. Furthermore, the mice kept in non-SPF conditions or old aged mice failed to establish the HBV persistence AHI with $6 \mu \mathrm{g}$ pAAV/HBV1.2 (data not shown). Consistent with this observation, clinical data have shown that chronic HBV infection mostly occurs in childhood but only $10 \%$ of them appears in adults $[29,30]$.

Nevertheless, it seems hard to explain a very low HBV persistence observed in mice AHI with $1 \mu \mathrm{g}$ low doses of pAAV/HBV1.2 plasmid [10]. Our previous studies revealed that HBV tolerance was mediated by HBsAg-specific $\operatorname{Tr} 1$ like cells and the time required for induction of these cells was at least 1 week $[13,17]$. It is likely that the amount of HBsAg in mice receiving
$1 \mu \mathrm{g}$ pAAV/HBV1.2 plasmid is too little to induce HBV tolerance.

To explore the potential pathogen recogntion receptors (PRRs) that are responsible for HBV clearance induced by $20 \mu \mathrm{g}$ plasmid DNA, we chose some TLR candidates that have interaction with DNA or RNA. Also, TLR4, a receptor recognizing bacterial liposaccarides, was tested to rule out the possibility that injected plasmid are mixed with LPS during plasmid DNA extraction in the present study. Our data suggest that TLRs signaling pathways are involved in suppressing HBV, but do not play a dominant role in final elimination of HBV caused by $20 \mu \mathrm{g} \mathrm{HBV-containing} \mathrm{plas-}$ mids, which is consistent with the report that serum HBsAg still disappear in Myd88 $8^{-/-}$Trif $^{-/-}$mice at week 6 AHI [31]. The precise mechanisms of which PRRs involved in HBV clearance in our model need further investigation.

In our model, we found the mRNA levels of $t$-bet and cxcr3 were up-regulated significantly in mice injected with $20 \mu \mathrm{g}$ pAAV/Control plasmids compared with mice injected with NS. T-bet is the transcription factor of Th1 cells and CXCR3 is the chemokine receptor expressed on Th1 cells [32]. These results further support a recent report that $\mathrm{CD}^{+}$Th1 cells played an important role in $\mathrm{HBV}$ clearance AHI with $20 \mu \mathrm{g}$ pAAV/HBV1.2 plasmid [16].

\section{Conclusion}

In this study we demonstrated that it is the dose of the plasmid backbone, but not HBV related antigens, regulates immune responses to determine HBV clearance in our mouse model. In addition, significantly increased mRNA levels of Th1-related immune factors teb-1, cxcr3 in the liver MNCs of mice receiving $20 \mu \mathrm{g}$ of the plasmid backbone DNA suggest the involvement of Th1 cells in determination of $\mathrm{HBV}$ persistence or clearance.

\section{Acknowledgements}

We thank Pei-Jer Chen (National Taiwan University) for kindly providing the HBV plasmids pAAV/HBV1.2 and e/core-null pAAV/HBV1.2. 


\section{Funding}

This work was supported by Natural Science Foundation of China [81401281], grants for scientific research of BSKY from Anhui Medical University [xj201401], grants for the 4th excellently scientific research of QNBJRC from Anhui Medical University [2013500023].

\section{Availability of data and materials}

Please contact author for data requests.

\section{Authors' contributions}

$\mathrm{XW}$ and JZ designed the study, performed the analyses, and wrote the manuscript. YZ, YL and TM contributed to the design of the study and performed analyses. QL and JX supervised the analyses. LX designed the study, supervised the analyses, and wrote the manuscript. XW and JZ contributed equally. All of the authors have read and approved the final manuscript.

\section{Ethics approval}

Animal experiment protocols were approved by Animal Care and Use Committee of Anhui Medical University. Mice used in this study were euthanized by suffocation with $\mathrm{CO}_{2}$.

\section{Competing interests}

The authors declare that they have no competing interests.

\section{Publisher's Note}

Springer Nature remains neutral with regard to jurisdictional claims in published maps and institutional affiliations.

\section{Author details}

${ }^{1}$ School of Basic Medical Sciences, Anhui Medical University, 81\#Mei Shan Road, Hefei 230032, Anhui, China. ${ }^{2}$ Pediatric Translational Medicine Institute, Shanghai Children's Medical Center, Shanghai Jiaotong University School of Medicine, Shanghai, China. ${ }^{3}$ Department of Pathology, The Second Affiliated Hospital of Anhui Medical University, Hefei, Anhui, China. ${ }^{4}$ Department of Spine Surgery, The First Affiliated Hospital of Anhui Medical University, Hefei, Anhui, China.

Received: 29 January 2018 Accepted: 13 May 2018

Published online: 21 May 2018

\section{References}

1. Ganem D, Varmus HE. The molecular biology of the hepatitis B viruses. Annu Rev Biochem. 1987;56:651-93.

2. Tsai KN, Kuo CF, Ou JJ. Mechanism of hepatitis B Vrius persistence. Trends Microbiol. 2018;26:33-42

3. Chen CJ, Yang HI, Su J, Jen CL, You SL, et al. Risk of hepatocellular carcinoma across a biological gradient of serum hepatitis B virus DNA level. JAMA. 2006:295:65-73.

4. Iloeje UH, Yang HI, Chen CJ. Natural history of chronic hepatitis B: what exactly has REVEAL revealed? Liver Int. 2012;32:1333-41.

5. Yan H, Zhong G, Xu G, He W, Jing Z, et al. Sodium taurocholate cotransporting polypeptide is a functional receptor for human hepatitis $B$ and D virus. elife. 2012:1:e00049.

6. Larkin J, Clayton M, Sun B, Perchonock CE, Morgan JL, et al. Hepatitis B virus transgenic mouse model of chronic liver disease. Nat Med. 1999:5:907-12.

7. Liu F, Song Y, Liu D. Hydrodynamics-based transfection in animals by systemic administration of plasmid DNA. Gene Ther. 1999:6:1258-66.

8. Yang PL, Althage A, Chung J, Chisari FV. Hydrodynamic injection of viral DNA: a mouse model of acute hepatitis B virus infection. Proc Natl Acad Sci U S A. 2002;99:13825-30.

9. Huang LR, Wu HL, Chen PJ, Chen DS. An immunocompetent mouse model for the tolerance of human chronic hepatitis B virus infection. Proc Natl Acad Sci U S A. 2006;103:17862-7.

10. Li L, Li S, Zhou Y, Yang L, Zhou D, et al. The dose of HBV genome contained plasmid has a great impact on HBV persistence in hydrodynamic injection mouse model. Virol J. 2017:14:205

11. Shen Z, Yang H, Yang S, Wang W, Cui X, et al. Hepatitis B virus persistence in mice reveals IL-21 and IL-33 as regulators of viral clearance. Nat Commun. 2017:8:2119.

12. Iurescia S, Fioretti D, Rinaldi M. A blueprint for DNA vaccine design Methods Mol Biol. 2014;1143:3-10.
13. Xu L, Yin W, Sun R, Wei H, Tian Z. Kupffer cell-derived IL-10 plays a key role in maintaining humoral immune tolerance in HBV-persistent mice. Hepatology. 2013;59:443-52.

14. Li F, Wei H, Gao Y, Xu L, Yin W, et al. Blocking the natural killer cell inhibitory receptor NKG2A increases activity of human natural killer cells and clears hepatitis B virus infection in mice. Gastroenterology. 2013;144:392-401.

15. Li M, Sun R, Xu L, Yin W, Chen Y, et al. Kupffer cells support hepatitis B virus-mediated CD8+ T cell exhaustion via hepatitis B Core antigen-TLR2 interactions in mice. J Immunol. 2015;195:3100-9.

16. Zheng $M$, Sun $R$, Wei $H$, Tian Z. NK cells help induce anti-hepatitis $B$ virus CD8+ T cell immunity in mice. J Immunol. 2016:196:4122-31.

17. $X u L$, Yin $W$, Sun $R$, Wei $H$, Tian Z. Liver type I regulatory $T$ cells suppress germinal center formation in HBV-tolerant mice. Proc Natl Acad Sci U S A. 2013;110:16993-8.

18. Zeng Z, Kong X, Li F, Wei H, Sun R, et al. IL-12-based vaccination therapy reverses liver-induced systemic tolerance in a mouse model of hepatitis $B$ virus carrier. J Immunol. 2013:191:4184-93.

19. Lin YJ, Huang LR, Yang HC, Tzeng HT, Hsu PN, et al. Hepatitis B virus core antigen determines viral persistence in a C57BL/6 mouse model. Proc Nat Acad Sci U S A. 2010:107:9340-5.

20. Sakurai H, Kawabata K, Sakurai F, Nakagawa S, Mizuguchi H. Innate immune response induced by gene delivery vectors. Int J Pharm. 2008;354:9-15.

21. Ma Z, Cao Q, Xiong Y, Zhang E, Lu M. Interaction between Hepatitis B Virus and toll-like receptors: current status and potential therapeutic use for chronic Hepatits B. Vaccines (Basel). 2018;6(1):E6.

22. Wu J, Lu M, Meng $Z$, Trippler $M$, Broering $R$, et al. Toll-like receptormediated control of HBV replication by nonparenchymal liver cells in mice. Hepatology. 2007:46:1769-78.

23. Schulte M, Sorkin M, Al-Benna S, Stupka J, Hirsch T, et al. Innate immune response after adenoviral gene delivery into skin is mediated by AIM2, NALP3, DAl and mda5. Spring. 2013;2:234

24. Xiao T. Innate immune recognition of nucleic acids. Immunol Res. 2009:43:98-108.

25. Gao B, Jeong WI, Tian Z. Liver: an organ with predominant innate immunity Hepatology. 2008:47:729-36.

26. Bottcher JP, Knolle PA, Stabenow D. Mechanisms balancing tolerance and immunity in the liver. Dig Dis. 2011:29:384-90.

27. Bowen DG, McCaughan GW, Bertolino P. Intrahepatic immunity: a tale of two sites? Trends Immunol. 2005:26:512-7.

28. Li F, Tian Z. The liver works as a school to educate regulatory immune cells. Cell Mol Immunol. 2013;10:292-302

29. Ganem D, Prince AM. Hepatitis B virus infection-natural history and clinical consequences. N Engl J Med. 2004;350:1118-29.

30. Liang TJ. Hepatitis B: the virus and disease. Hepatology. 2009:49:S13-21.

31. Ma Z, Liu J, Wu W, Zhang E, Zhang $X$, et al. The IL-1R/TLR signaling pathway is essential for efficient CD8+ T-cell responses against hepatitis $B$ virus in the hydrodynamic injection mouse model. Cell Mol Immunol. 2017;14:997-1008.

32. Zhang $Y$, Zhang $Y$, Gu W, Sun B. TH1/TH2 cell differentiation and molecular signals. Adv Exp Med Biol. 2014;841:15-44.

\section{Ready to submit your research? Choose BMC and benefit from:}

- fast, convenient online submission

- thorough peer review by experienced researchers in your field

- rapid publication on acceptance

- support for research data, including large and complex data types

- gold Open Access which fosters wider collaboration and increased citations

- maximum visibility for your research: over $100 \mathrm{M}$ website views per year

\section{At BMC, research is always in progress.}

Learn more biomedcentral.com/submissions 